\title{
Simultaneous detection of multiple mycotoxins in broiler feeds using a liquid chromatography tandem-mass spectrometry
}

\author{
Jutamart KONGKAPAN ${ }^{1,2)}$, Saranya POAPOLATHEP ${ }^{3)}$, Supaporn ISARIYODOM ${ }^{4)}$, Susumu KUMAGAI ${ }^{5)}$ and \\ Amnart POAPOLATHEP $1,2,3) *$ \\ 1) Interdisciplinary Graduate Program in Agricultural Biotechnology, Graduate School, Kasetsart University, KamphaengSaen Campus, \\ Nakhon, Pathom 73140, Thailand \\ ${ }^{2)}$ Center of Excellence on Agricultural Biotechnology: (AG-BIO/PERDO-CHE), Bangkok 10900, Thailand \\ ${ }^{3)}$ Department of Pharmacology, Faculty of Veterinary Medicine, Kasetsart University, Bangkok 10900, Thailand \\ 4) Department of Animal Science, Faculty of Agriculture, Kasetsart University, Bangkok 10900, Thailand \\ ${ }^{5)}$ Food Safety Commission, Minato-Ku, Tokyo 107-6122, Japan
}

(Received 28 May 2015/Accepted 25 September 2015/Published online in J-STAGE 16 October 2015)

ABSTRACT. Mycotoxins are secondary fungal metabolites that are typically present in grain and feed ingredients used for animal feeds. An analytical method using LC-ESI-MS/MS was developed to quantify nine mycotoxins, consisting of aflatoxin $\mathrm{B}_{1}\left(\mathrm{AFB}_{1}\right), \mathrm{AFB}_{2}, \mathrm{AFG}_{1}$, $\mathrm{AFG}_{2}, \mathrm{~T}-2$ toxin, deoxynivalenol (DON), nivalenol (NIV), zearalenone (ZEA) and ochratoxin A (OTA) in broiler feeds. In total, 100 samples of broiler feeds were collected from poultry farms in Central Thailand. The survey found that $\mathrm{AFB}_{1}$ and ZEA were the most prevalent mycotoxins in the feed samples at percentages of $93 \%$ and $63 \%$, respectively. The limit of detections (LODs) of investigated mycotoxins was $0.20-0.78 \mathrm{ng} / \mathrm{g}$. $\mathrm{AFB}_{2}, \mathrm{DON}, \mathrm{AFG}_{1}, \mathrm{NIV}$ and T-2 toxin were also detectable at low contamination levels with percentages of $20 \%, 9 \%, 7 \%, 5 \%$ and $1 \%$, respectively, whereas $\mathrm{OTA}_{\text {and }} \mathrm{AFG}_{2}$ were not detected in any of the feed samples. These results suggest that there is a very low level of risk of the exposure to mycotoxins in feeds obtained from broiler farms in Central Thailand.

KEY WORDS: broiler feed, LC-ESI-MS/MS, mycotoxin contamination

doi: 10.1292/jvms.15-0317; J. Vet. Med. Sci. 78(2): 259-264, 2016

Mycotoxins are toxic secondary metabolites produced by filamentous fungi that are ubiquitous contaminants in agricultural commodities which are present in many feed and foodstuffs. The major genera of mycotoxin-producing fungi include; Aspergillus, Fusarium and Penicillium that frequently occur in major food crops in the field and result in contamination during storage. Mycotoxins can appear in the food chain, either by being consumed directly by humans or by use as livestock feed. Exposure of animals to mycotoxins can result in mycotoxin accumulation in different organs and tissues, thus entering the human food chain through animal products, such as meat, milk or eggs. The Food and Agricultural Organization of the United Nations (FAO) has estimated that up to $25 \%$ of the world's food crops are significantly contaminated with mycotoxins [13]. Poultry are highly susceptible to mycotoxicoses caused by aflatoxins $\left(\mathrm{AFB}_{1}, \mathrm{AFB}_{2}, \mathrm{AFG}_{1}\right.$ and $\left.\mathrm{AFG}_{2}\right)$, ochratoxin $\mathrm{A}(\mathrm{OTA})$, zearalenone (ZEA), deoxynivalenol (DON), fumonisins $\left(\mathrm{FB}_{1}\right.$ and $\mathrm{FB}_{2}$ ), T-2 and HT-2 toxin [11]. The co-occurrence of multiple mycotoxins implies a potential risk of additional or even synergistic toxic effects after consumption of contaminated food or feed commodities [15].

*Correspondence to: Poapolathep, A., Department of Pharmacology, Faculty of Veterinary Medicine, Kasetsart University, Bangkok 10900, Thailand. e-mail: fvetamp@ku.ac.th; fvetamp@hotmail.com (C)2016 The Japanese Society of Veterinary Science

This is an open-access article distributed under the terms of the Creative Commons Attribution Non-Commercial No Derivatives (by-nc-nd) License $<$ http://creativecommons.org/licenses/by-nc-nd/3.0/>.
The negative effects of mycotoxins on chicken performance have been demonstrated in numerous studies. For example, feeding a high level $(3.5 \mathrm{mg} / \mathrm{kg}$ of feed) of an AF mixture (i.e. $79 \% \mathrm{AFB}_{1}, 16 \% \mathrm{AFG}_{1}, 4 \% \mathrm{AFB}_{2}$ and $1 \%$ $\mathrm{AFG}_{2}$ ) to broilers reduced their body weight and increased their liver and kidney weights [16]. Fusarium mycotoxins have been shown to adversely affect poultry. In addition to reduced feed intake and body weight gain, buccal-oral ulceration and plaque formation were observed when 7-dayold chicks were given T-2 toxin (4 or16 mg/kg of feed) or diacetoxyscirpenol (DAS) (4 or $16 \mathrm{mg} / \mathrm{kg}$ of feed). Similar effects were also observed in 1-day-old to 3-week-old chicks consuming T-2 toxin at $6 \mathrm{mg} / \mathrm{kg}$ of feed and in 24-25-weekold hens consuming DAS at $20 \mathrm{mg} / \mathrm{kg}$ of feed. Poultry also are adversely affected by both T-2 and DON, but are very resistant to the estrogenic effects of ZEA [3].

Thailand is located in the tropical zone, where there is a high risk of mycotoxin exposure; however, scientific reports on mycotoxins occurrence are limited. Studies indicated frequent contamination of foodstuff in this region with aflatoxins in peanut [21], deoxynivalenol in wheat products [10] and coincidental contamination with fumonisins and aflatoxins in corn samples [23]. More recent studies revealed frequent contamination of aflatoxins in black glutinous rice, brown rice, white rice, white glutinous rice and wheat flour as well as of zearalenone in corn kernels intended for human consumption [14]. Anukul et al. [1] discussed the recent findings of mycotoxins in food and feed, with emphasis on aflatoxins, fumonisins, ochratoxins and zearalenone.

To date, there has been an increase in the number of re- 
strictive mycotoxin categories in foods and a reduction in the acceptable permitted levels in foods and feeds defined by the European Union and other developed countries [5, 6]. The analysis of mycotoxins is challenging as they are usually present in low concentrations in complex matrices, and they may occur in various combinations produced by a single or by several fungal species. During the last decade, liquid chromatography tandem mass spectrometry (LC-MS/MS) has been established as a powerful tool for the identification of mycotoxins in food [12]. Furthermore, the simultaneous determination of multi-component mycotoxin contaminants in food and feed was performed by LC-MS/MS [2, 12, 17, $18]$.

The current study was conducted to develop an analytical method for the simultaneous determination of multiple mycotoxins $\left(\mathrm{AFB}_{1}, \mathrm{AFB}_{2}, \mathrm{AFG}_{1}, \mathrm{AFG}_{2}, \mathrm{~T}-2, \mathrm{DON}, \mathrm{NIV}, \mathrm{ZEA}\right.$ and OTA) in broiler feeds by using LC-ESI-MS/MS.

\section{MATERIALS AND METHODS}

Chemicals and reagents: The analytical standards of the mycotoxins, $\mathrm{AFB}_{1}, \mathrm{AFB}_{2}, \mathrm{AFG}_{1}, \mathrm{AFG}_{2}, \mathrm{~T}-2$ toxin, $\mathrm{DON}$, NIV, ZEA and OTA, were purchased from Sigma-Aldrich (St. Louis, MO, U.S.A.). De-ionized distilled water was produced using the Milli-Q purification system from Millipore, Inc. (Bedford, MA, U.S.A.). HPLC grade acetronitrile and acetic acid were obtained from Burdick \& Jackson (Ulsan, Korea), while ammonium acetate was purchased from Ajax Finechem Pty Ltd. (Taren Point, NSW, Australia).

Stock and working standard preparation: Combinations of standard mycotoxin stocks were prepared in methanol at a concentration of $1,000 \mathrm{ng} / \mathrm{m} \mathrm{l}$ for the high sensitivity group $\left(\mathrm{AFB}_{1}, \mathrm{AFB}_{2}, \mathrm{AFG}_{1}\right.$, OTA and T-2) and for the low sensitivity group $\left(\mathrm{AFG}_{2}\right.$, DON, ZEA and NIV). The working standard solutions were prepared by diluting this stock of standard mixture with methanol at different concentration ranges as follows: $1.0-250 \mathrm{ng} / \mathrm{ml}$ for the high sensitivity group and $2.0-500 \mathrm{ng} / \mathrm{ml}$ for the low sensitivity group.

Sampling and sample preparation: In total, 100 broiler feed samples (10 feed samples per each province) were randomly collected from broiler farms in Central Thailand from Bangkok, Pathum Thani, Nakhon Nayok, Nakhon Pathom, Ayutthaya, Saraburi, Lopburi, Supanburi, Chainart, Uthai Thani and Nakhonsawan provinces. In this study, the collected samples were commercial feed that were produced in Thailand. The major ingredients in broiler feed samples include corn, fish meal and soybean. The feed samples were kept at $-20^{\circ} \mathrm{C}$ until analysis.

The feed samples were blended, and then, a $10 \mathrm{~g}$ ground feed sample was homogenized with $40 \mathrm{~m} l$ of the organic extraction solvent mixture (acetronitrile:water:acetic acid, 79:20:1 v/v) by shaking for $60 \mathrm{~min}$. The crude extract was centrifuged at $1,509 \mathrm{~g}$ for $10 \mathrm{~min}$ as described by Soleimany et al. [17]. Then, $0.5 \mathrm{~m} l$ of the supernatant was diluted in 4.5 $\mathrm{m} l$ of acetronitrile:water:acetic acid, 20:79:1 v/v. The extract was filtered by passing through a $0.22 \mu \mathrm{m}$ syringe filter and then injected into the unit for LC-MS/MS [17, 18].

LC-MS/MS equipment and parameters: LC analysis was performed using an Agilent 1260 infinity (Agilent Technologies, Waldbronn, Germany) consisting of a binary pump, a degasser, a column oven and an auto sampler. The chromatographic separation was performed on a ZORBAX Eclipse Plus RRHT C18 column $(50 \times 2.1 \mathrm{~mm}, 1.8 \mu \mathrm{m}$ particle size $)$. The column was maintained at $40^{\circ} \mathrm{C}$. The mobile phase consisted of $5 \mathrm{mM}$ ammonium acetate with $0.2 \%$ acetic acid in water (mobile phase $\mathrm{A}$ ) and $0.2 \%$ acetic acid in acetonitrile (mobile phase B). The gradient program of the mobile phase was as follows: 10\% B (initial for $1 \mathrm{~min}), 10-95 \% \mathrm{~B}(5 \mathrm{~min})$ and $95 \% \mathrm{~B}(10 \mathrm{~min})$. The column was re-equilibrated for 3.5 min between injections. The mobile phase solution was filtered through a $0.22 \mu \mathrm{m}$ membrane and ultrasonically degassed prior to application. The flow rate was $0.5 \mathrm{ml} / \mathrm{min}$, while the injection volume was $10 \mu l$.

The mass spectrometer used was a triple quadrupole mass spectrometer (6460 triple, Agilent Technologies) equipped with an electrospray ionization source run in both positive and negative ion modes under the multiple reaction monitoring mode (MRM). The ionization source parameters were optimized as follows: capillary voltage, 3,500 V; gas temperature, $320^{\circ} \mathrm{C}$; gas flow rate, $8 \mathrm{l} / \mathrm{min}$; and nebulizer, $50 \mathrm{psi}$. The parameters (for the mass spectrometer) were optimized as shown in Table 1.

Method validation: Validation of the LC-MS/MS method was performed to assess the efficiency of this analytical method by investigating the selectivity, sensitivity, accuracy and precision in accordance with the European Commission regulation for the performance of analytical methods [4].

Linearity: The linearity of an analytical procedure is its ability (within a given range) to obtain test results that are directly proportional to the concentration (amount) of analyte in the sample. Linear regression analysis was conducted for the mycotoxin standard mixtures of the $\mathrm{AFB}_{1}, \mathrm{AFB}_{2}$, $\mathrm{AFG}_{1}, \mathrm{AFG}_{2}$, OTA, T-2, ZEA, DON and NIV toxins under the optimized LC-MS/MS conditions. Eight-point calibration curves were plotted as the peak area ratio $(y)$ of each mycotoxin against its concentration $(\mathrm{y}=\mathrm{mx} \pm \mathrm{c})$ at the concentration ranges of 1.0-250 $\mathrm{ng} / \mathrm{ml}$ for $\mathrm{AFB}_{1}, \mathrm{AFB}_{2}, \mathrm{AFG}_{1}$, $\mathrm{T}-2$ and OTA; and 2-500 $n \mathrm{~g} / \mathrm{m} l$ for $\mathrm{AFG}_{2}, \mathrm{DON}, \mathrm{ZEA}$ and NIV. The linearity was assessed using the correlation coefficient $\left(r^{2}\right)$ (Table 2).

Limit of detection and limit of quantification: The limit of detection (LOD) corresponds to the concentration that will give a signal-to-noise $(\mathrm{S} / \mathrm{N})$ ratio of $3: 1$. The limit of quantification (LOQ) is defined as the concentration of related substance in the sample that will give an $\mathrm{S} / \mathrm{N}$ ratio of 10:1 (Table 2).

Recovery and precision: Recovery and precision (repeatability, expressed as relative standard deviation (RSD) in \%) were determined within-day by analyzing seven replicates containing nine mycotoxins at three different QC levels (Table 3). The inter-day precisions were determined by analyzing QC samples on five different days (one batch per day) (Table 3). 
Table 1. MS/MS parameters for the determination of nine mycotoxins

\begin{tabular}{|c|c|c|c|c|c|c|}
\hline Mycotoxins & $\begin{array}{l}\text { Precusor ion } \\
\qquad(\mathrm{m} / \mathrm{z})\end{array}$ & $\begin{array}{l}\text { Product ions } \\
\qquad(\mathrm{m} / \mathrm{z})\end{array}$ & $\begin{array}{c}\text { Collision energy } \\
(\mathrm{eV})\end{array}$ & $\begin{array}{l}\text { Retention time } \\
\quad(\min )\end{array}$ & $\begin{array}{l}\text { Fragmentor } \\
(\mathrm{eV})\end{array}$ & $\begin{array}{l}\text { Ionization } \\
\text { mode }\end{array}$ \\
\hline \multirow[t]{2}{*}{$\mathrm{AFB}_{1}$} & 313.07 & 285.1 & 21 & 5.13 & 150 & $\mathrm{ESI}^{+}$ \\
\hline & 313.07 & 241.0 & 35 & & 150 & \\
\hline \multirow[t]{2}{*}{$\mathrm{AFB}_{2}$} & 315.09 & 287.1 & 25 & 4.99 & 160 & $\mathrm{ESI}^{+}$ \\
\hline & 315.09 & 259.0 & 29 & & 160 & \\
\hline \multirow[t]{2}{*}{$\mathrm{AFG}_{1}$} & 329.07 & 311.0 & 21 & 4.98 & 150 & $\mathrm{ESI}^{+}$ \\
\hline & 329.07 & 243.0 & 25 & & 150 & \\
\hline \multirow[t]{2}{*}{$\mathrm{AFG}_{2}$} & 331.08 & 313.0 & 21 & 4.85 & 170 & $\mathrm{ESI}^{+}$ \\
\hline & 331.08 & 245.0 & 29 & & 170 & \\
\hline \multirow[t]{2}{*}{$\mathrm{T}-2$} & 489.40 & 387.3 & 20 & 5.6 & 170 & $\mathrm{ESI}^{+}$ \\
\hline & 489.40 & 245.2 & 26 & & 170 & \\
\hline \multirow[t]{2}{*}{ OTA } & 404.00 & 192.9 & 48 & 5.78 & 130 & $\mathrm{ESI}^{+}$ \\
\hline & 404.00 & 102.1 & 80 & & 130 & \\
\hline \multirow[t]{2}{*}{ ZEA } & 319.16 & 283.0 & 5 & 5.94 & 80 & $\mathrm{ESI}^{+}$ \\
\hline & 319.16 & 187.0 & 17 & & 80 & \\
\hline \multirow[t]{2}{*}{ DON } & 355.10 & 265.1 & 4 & 3.5 & 90 & $\mathrm{ESI}^{-}$ \\
\hline & 355.10 & 59.1 & 10 & & 90 & \\
\hline \multirow[t]{2}{*}{ NIV } & 371.10 & 281.0 & 4 & 2.1 & 80 & $\mathrm{ESI}^{-}$ \\
\hline & 371.10 & 59.1 & 10 & & 80 & \\
\hline
\end{tabular}

$\mathrm{AFB}_{1}$, aflatoxin $\mathrm{B}_{1} ; \mathrm{AFB}_{2}$, aflatoxin $\mathrm{B}_{2} ; \mathrm{AFG}_{1}$, aflatoxin $\mathrm{G}_{1} ; \mathrm{AFG}_{2}$, aflatoxin $\mathrm{G}_{2} ; \mathrm{OTA}$, Ochratoxin $\mathrm{A} ; \mathrm{ZEA}$, Zearalenone; $\mathrm{DON}$, Deoxynivalenol; NIV, Nivalenol; $\mathrm{ESI}^{+}$, electrospray ionization in positive mode; $\mathrm{ESI}^{-}$, electrospray ionization in negative mode.

Table 2. Linearity, limit of detection (LOD) and limit of quantification (LOQ) of the optimized LC-MS/MS method for simultaneous determination of mycotoxins

\begin{tabular}{ccccc}
\hline Mycotoxins & $\begin{array}{c}\text { LOD in feed } \\
\text { sample }(n \mathrm{~g} / \mathrm{g})\end{array}$ & $\begin{array}{c}\text { LOQ in feed } \\
\text { sample }(n \mathrm{~g} / \mathrm{g})\end{array}$ & $\begin{array}{c}\text { Linear range } \\
(n \mathrm{~g} / \mathrm{g})\end{array}$ & $r^{2}$ \\
\hline $\mathrm{AFB}_{1}$ & 0.39 & 1.0 & $1.0-250$ & 0.9993 \\
$\mathrm{AFB}_{2}$ & 0.48 & 1.0 & $1.0-250$ & 0.9989 \\
$\mathrm{AFG}_{1}$ & 0.20 & 1.0 & $1.0-250$ & 0.9995 \\
$\mathrm{AFG}$ & 0.78 & 2.0 & $2.0-500$ & 0.9986 \\
$\mathrm{~T}-2$ & 0.39 & 1.0 & $1.0-250$ & 0.9963 \\
OTA & 0.39 & 1.0 & $1.0-250$ & 0.9991 \\
ZEA & 0.78 & 2.0 & $2.0-500$ & 0.9970 \\
DON & 0.78 & 2.0 & $2.0-500$ & 0.9989 \\
NIV & 0.78 & 2.0 & $2.0-500$ & 0.9999 \\
\hline
\end{tabular}

$r^{2}$, correlation coefficient.

\section{RESULTS}

Optimization of LC-MS/MS conditions: For the multimycotoxin method, it was decided to perform simultaneous determination within a single run with detection in positive and negative modes. In both ionization modes, the best sensitivity for all investigated compounds was achieved using $5 \mathrm{mM}$ ammonium acetate in $0.2 \%$ acetic acid (mobile phase A) and $0.2 \%$ acetic acid in acetronitrile (mobile phase B) as the mobile phase. In addition, nearly all compounds could be separated, except $\mathrm{AFG}_{1}$ and $\mathrm{AFB}_{2}$, which eluted at the same retention time (Fig. 1). The differentiation of $\mathrm{AFG}_{1}$ and $\mathrm{AFB}_{2}$, the $[\mathrm{M}+\mathrm{H}]^{+}$mass numbers of which are 329.07 and 315.09 , respectively, could be achieved by the difference of characteristic parent ions in the multiple reaction monitor (MRM) mode. Furthermore, when considering that the selected product ions were $329.07>311,329.07>243$ and $315.09>287.1,315.09>259$ for $\mathrm{AFG}_{1}$ and $\mathrm{AFB}_{2}$, respectively, the selectivity of daughter ions could not disturb each other.

LC-MS/MS validation method: The linearity and sensitivity results are reported in Table 2 . The method exhibited good linearity over the relevant working range, with $r^{2}$ values between 0.9963 (for T-2) and 0.9999 (for NIV). The LOD and LOQ values in matrices ranged from 0.20 to 0.78 $n \mathrm{~g} / \mathrm{g}$ and from 0.78 to $1.56 \mathrm{ng} / \mathrm{g}$, respectively (Table 2). The recoveries were obtained within the range of $81-103 \%$ for all nine mycotoxins, as summarized in Table 3.

Occurrence of the mycotoxins in broiler feeds: The 100 broiler feed samples were quantified for the nine mycotoxins studied by simultaneous determination using LC-MS/MS. In summary, $93 \%$ of the samples contained $\mathrm{AFB}_{1}$ at concentrations ranging from 0.47 to $8.52 \mathrm{ng} / \mathrm{g}$. The second most prevalent mycotoxin was ZEA found in $63 \%$ of the samples at concentrations ranging from 2.22 to $263.51 \mathrm{ng} / \mathrm{g}$. The other mycotoxins found to be contaminating feed samples were $\mathrm{AFB}_{2}, \mathrm{DON}, \mathrm{AFG}_{1}, \mathrm{NIV}$ and T-2 in $20 \%, 9 \%, 7 \%, 5 \%$ and $1 \%$, respectively, of samples. In the present study, $\mathrm{AFG}_{2}$ and OTA were not detectable in broiler feed samples (Table 4). The co-occurrence of mycotoxins was also detected in broiler feeds, with $\mathrm{AFB}_{1}$ and ZEA in 46 of 100 feed samples, $\mathrm{AFB}_{1}$ and DON in 9 of 100 feed samples, $\mathrm{AFB}_{1}$ and NIV in 4 of 100 feed samples, $\mathrm{AFB}_{1}, \mathrm{AFB}_{2}$ and $\mathrm{ZEA}$ in 13 of the 100 feed samples and aflatoxins $\left(\mathrm{AFB}_{1}, \mathrm{AFB}_{2}\right.$ and $\left.\mathrm{AFG}_{1}\right)$ in 4 of the 100 feed samples. 
Table 3. Accuracy and precision for mycotoxin determination in optimal LC-MS/MS conditions for spiked broiler feed samples

\begin{tabular}{lcccc}
\hline Mycotoxins & $\begin{array}{c}\text { Spiking level } \\
(n \mathrm{~g} / \mathrm{g})\end{array}$ & $\begin{array}{c}\text { Recovery } \\
(\%)\end{array}$ & $\begin{array}{c}\text { Intra-day precision } \\
(\% \mathrm{RSD})\end{array}$ & $\begin{array}{c}\text { Inter-day precision } \\
(\% \mathrm{RSD})\end{array}$ \\
\hline $\mathrm{AFB}_{1}$ & 2 & 96 & 5.46 & 6.37 \\
& 10 & 98 & 3.37 & 5.43 \\
$\mathrm{AFB}_{2}$ & 50 & 101 & 3.42 & 3.89 \\
& 2 & 97 & 6.38 & 7.98 \\
& 10 & 95 & 4.43 & 4.64 \\
$\mathrm{AFG}_{1}$ & 50 & 98 & 2.21 & 3.17 \\
& 2 & 92 & 3.61 & 3.77 \\
& 10 & 95 & 4.86 & 4.22 \\
$\mathrm{AFG}_{2}$ & 50 & 103 & 2.70 & 3.45 \\
& 10 & 91 & 2.59 & 2.96 \\
& 50 & 96 & 7.28 & 7.67 \\
$\mathrm{~T}-2$ & 200 & 88 & 5.76 & 7.11 \\
& 2 & 92 & 6.41 & 6.11 \\
& 10 & 87 & 5.53 & 5.79 \\
$\mathrm{OTA}$ & 50 & 95 & 3.15 & 3.48 \\
& 2 & 89 & 5.13 & 4.35 \\
& 10 & 85 & 4.64 & 3.87 \\
$\mathrm{ZEA}$ & 50 & 86 & 3.79 & 3.82 \\
& 10 & 93 & 3.63 & 4.05 \\
& 50 & 94 & 5.02 & 4.69 \\
$\mathrm{DON}$ & 200 & 92 & 1.78 & 1.98 \\
& 10 & 82 & 5.46 & 4.86 \\
$\mathrm{NIV}$ & 50 & 84 & 3.37 & 3.51 \\
& 200 & 85 & 3.42 & 2.89 \\
& 10 & 82 & 2.51 & 3.15 \\
& 50 & 81 & 1.87 & 2.03 \\
& 200 & 84 & 2.27 & 1.89 \\
\hline
\end{tabular}

\section{DISCUSSION}

The results illustrated that $\mathrm{AFB}_{1}$ and $\mathrm{ZEA}$ were the most common of the contaminants in broiler feed. On the other hand, detection ratios of DON and NIV, which are Fusarium toxins, are very low due to the compositions of such feed samples. Accordingly, processing and other ingredients, such as corn, soybean and fish meal, can also play a role regarding $\mathrm{AFB}_{1}$ and $\mathrm{ZEA}$ contaminations in broiler feed samples. The levels of mycotoxin contamination in the samples were below the regulatory limits, which corresponded to the U.S. Food and Drug Administration advisory level (FDA). These results suggest that risk of the exposure to mycotoxins in completed feeds obtained from broiler farms in Central Thailand is very low. On the other hand, low concentrations of mycotoxin contaminants, such as aflatoxins, trichothecenes and zearalenone, can cause a reduction in growth performance in pigs and broilers [8]. Moreover, the co-contamination of mycotoxins usually occurs in food or feeds, which can increase the potency of toxicity to the animals. Poor management of farm animals, especially with regard to farm feed storage and farm feeding, may have a major influence on the level of mycotoxin contamination in broiler feeds and relate to increased mycotoxin production [24]. The result of the present study corresponded well with the study of Streit et al. [19], since they also surveyed the contamination of mycotoxins in finished feed samples, with 2,743 samples analyzed over a period of 8 years (2004-2011). They found that Fumonisins, DON, ZEA, AF and OTA were the most prevalent in finished feed samples in South-East Asia. Khatoon et al. [9] also reported that the contamination of NIV and DON was found with relatively low level in broiler feeds in Pakistan. However, an UHPLCMS/MS-based method for the determination of 191 mycotoxins and other fungal metabolites was developed [20]. They reported that UHPLC-MS/MS allowed better separation of the analytes from the matrix. Regarding the method validation, the recovery levels were slightly better than those reported by Ren et al. [11] (76.2-102\%), Yibadatihan et al. [22] (81-112\%) and Soleimany et al. [17] (76.8-108.4\%). The intra- and inter-day precision values were in the range of $1.8-7.3 \%$ and $1.9-7.7 \%$, respectively. All the recovery and precision results were in agreement with performance criteria recommended by European Commission Regulation No. 401/2006 /EC [7].

In summary, an analytical method was developed for the simultaneous determination of nine mycotoxins in broiler feeds by using LC-MS/MS. This method can detect mycotoxins within a single run. The analytical method was demonstrated to be an excellent tool for unambiguous identifica- 

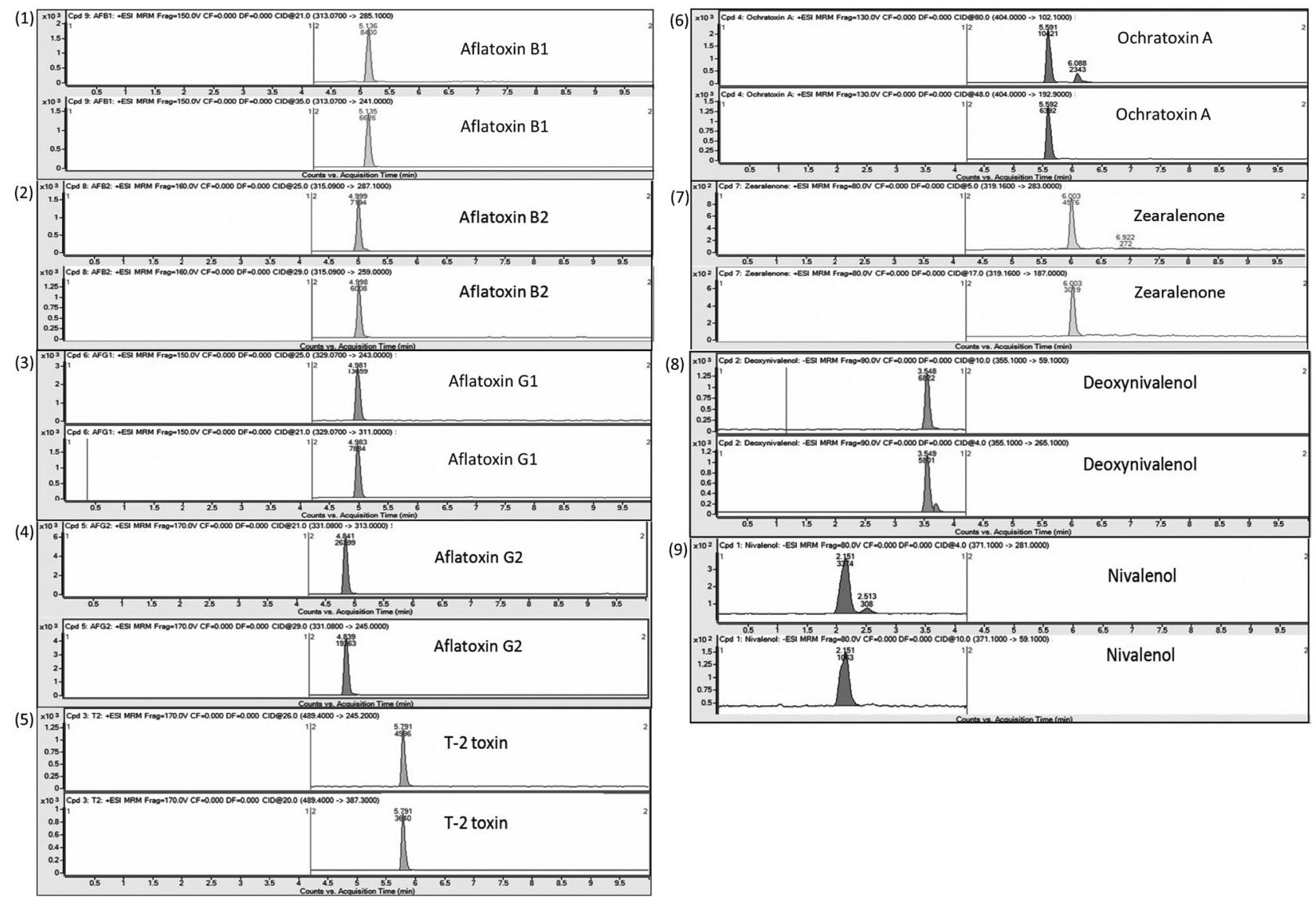

Fig. 1. LC-MS/MS extracted ion chromatogram of the spiked broiler feed sample for mycotoxins under optimized conditions of aflatoxin $B_{1}$, aflatoxin $B_{2}$, aflatoxin $G_{1}$, aflatoxin $G_{2}$, T-2 toxin, ochratoxin $A$, zearalenone, deoxynivalenol and nivalenol. Two mass transitions per each analyte were determined for quantification and identification. Upper chromatogram for each toxin represents the quantifier transition ion, whereas lower chromatogram represents the qualifier transition ion.

Table 4. Occurrence of mycotoxins in broiler feeds (total of 100 samples)

\begin{tabular}{cccc}
\hline Mycotoxins & $\begin{array}{c}\text { Percentage of positive } \\
\text { samples }\end{array}$ & $\begin{array}{c}\text { Range of concentration level } \\
\text { of contaminations }(\mathrm{ng} / \mathrm{g})\end{array}$ & $\begin{array}{c}\text { Mean of concentration } \\
(\mathrm{ng} / \mathrm{g})\end{array}$ \\
\hline $\mathrm{AFB}_{1}$ & 93 & $0.47-8.52$ & 2.02 \\
$\mathrm{AFB}_{2}$ & 20 & $0.79-3.30$ & 1.87 \\
$\mathrm{AFG}_{1}$ & 7 & $0.66-1.89$ & 1.30 \\
$\mathrm{AFG}$ & $\mathrm{ND}$ & 1.15 & $\mathrm{ND}$ \\
$\mathrm{T}-2$ & 1 & $\mathrm{ND}$ & 1.15 \\
$\mathrm{OTA}$ & $\mathrm{ND}$ & $2.22-263.51$ & $\mathrm{ND}$ \\
$\mathrm{ZEA}$ & 63 & $33.58-60.81$ & 84.27 \\
$\mathrm{DON}$ & 9 & $12.75-35.83$ & 45.05 \\
$\mathrm{NIV}$ & 5 & 27.26 \\
\hline
\end{tabular}

Mean of Concentration $(\mathrm{ng} / \mathrm{g})$ is the mean of the positive samples. ND=Not detected (lower than LOD).

tion of mycotoxins using the retention time, accurate mass of precursor and product ions. Furthermore, this is the first study to present data on multi-toxin occurrence in completed feeds obtained from broiler farms in Thailand using LC-ESIMS/MS. The results of mycotoxin contamination in broiler feeds showed that aflatoxins are the most common present mycotoxin (mainly $\mathrm{AFB}_{1}$ ) and can co-occur with other my- cotoxins ( $\mathrm{AFB}_{1}$ and $\left.\mathrm{ZEA}\right)$. This evidence highlighted that the production of mycotoxins differs according to the climatic conditions especially as Thailand is located in the tropical zone and the climatic conditions which are suitable for mycotoxin production. Nevertheless, the levels of mycotoxin contamination in the feeds were below the U.S. Food and Drug Administration advisory levels (FDA). These results 
also suggest that the risk level of exposure to mycotoxins in completed feeds obtained from brolier farms in Central Thailand is very low due to the low level contamination.

ACKNOWLEDGMENTS. The authors acknowledge the Royal Golden Jubilee Ph.D. Program, The Thailand Research Fund Bangkok, Thailand, Center for Agricultural Biotechnology, Kasetsart University, KamphaengSaen Campus, Nakhon Pathom and the Center of Excellence on Agricultural Biotechnology: (AG-BIO/PERDO-CHE) for providing funds. Finally, we would like to thank our colleagues at the Department of Pharmacology in Veterinary Medicine, Kasetsart University.

\section{REFERENCES}

1. Anukul, N., Kanithaporn, V. and Mahakarnchanakul, W. 2013. Significance of regulation limits in mycotoxin contamination in Asia and risk management programs at the national level. $J$. Food Drug Anal. 21: 227-241. [CrossRef]

2. Arroyo-Manzanares, N., Huertas-Pérez, J. F., García-Campaña, A. M. and Gámiz-Gracia, L. 2014. Simple methodology for the determination of mycotoxins in pseudocereals, spelt and rice. Food Contr. 36: 94-101. [CrossRef]

3. Cheeke, P. R. 1998. Mycotoxins in cereal grains and supplements. pp. 87-136. In: Natural Toxicants in Feeds, Forages, and Poisonous Plants. Interstate Publishers, Danville.

4. Commission Decision of 12 August 2002. Implementing Council Directive 96/23/EC concerning the performance of analytical methods and the interpretation of results. Off. J. Eur. Commun. L221/8-36, 17 August 2002.

5. Commission Regulation No. [EC] 466/2001 of 8 March 2001. Setting maximum levels for certain contaminants in foodstuffs. Off. J. Eur. Commun. L77/1-13, 16 March 2001.

6. Commission Regulation [EC] No. 472/2002 of 12 March 2002. Amending Regulation (EC) No. 466/2001 setting maximum levels for certain contaminants in foodstuffs. Off. J. Eur. Commun. L75: 16.

7. Commission Regulation [EC] No. 401/2006 of 23 February 2006. Laying down the methods of sampling and analysis for the official control of the levels of mycotoxins in foodstuffs. Off. $J$. Eur. Commun. L70/12-34, 9 March 2006.

8. Dersjant-Li, Y., Verstegen, M. W. A. and Gerrits, W. J. J. 2003. The impact of low concentrations of aflatoxin, deoxynivalenol or fumonisin in diets on growing pigs and poultry. Nutr. Res. Rev. 16: 223-239. [Medline] [CrossRef]

9. Khatoon, S., Hanif, N. Q., Tahira, I., Sultana, N., Sultana, K. and Ayub, N. 2012. Natural occurrence of aflatoxins, zearalenone and trichothecenes in maize grown in Pakistan. Pak. J. Bot. 44: 231-236.

10. Poapolathep, A., Poapolathep, S., Klangkaew, N., SugitaKonishi, Y. and Kumagai, S. 2008. Detection of deoxynivalenol contamination in wheat products in Thailand. J. Food Prot. 71: 1931-1933. [Medline]

11. Poornima, K. and Palanisamy, A. 2013. Mycoflora and multitoxin analysis of poultry raw materials and biocontrol of myco- flora by medicinal plant extracts. Int. J. Adv. Pharm. Biol. Chem. 2: 265-271.

12. Ren, Y., Zhang, Y., Shao, S., Cai, Z., Feng, L., Pan, H. and Wang, Z. 2007. Simultaneous determination of multi-component mycotoxin contaminants in foods and feeds by ultra-performance liquid chromatography tandem mass spectrometry. J. Chromatogr. A 1143: 48-64. [Medline] [CrossRef]

13. Rice, L. G. and Ross, F. B. 1994. Method for detection and quantification of fumonisins in corn, cereal products and animal excreta. J. Food Prot. 57: 36-40.

14. Singkong, W., Ratanapol, H. and Liamkaew, W. 2013. Zearalenone contamination in corn for human consumption in Kamphaengphet, Thailand. Chiang Mai. J. Sci. 40: 534-539.

15. Škrbić, B., Godula, M., Đurišić-Mladenović, N. and Živančev, J. 2011. Multi-mycotoxin analysis by UHPLC-HESI-MS/MS: a preliminary survey of Serbian wheat flour. Agron. Res. 9: 461-468.

16. Smith, E. E., Kubena, L. F., Braithwaite, C. E., Harvey, R. B., Phillips, T. D. and Reine, A. H. 1992. Toxicological evaluation of aflatoxin and cyclopiazonic acid in broiler chickens. Poult. Sci. 71: 1136-1144. [Medline] [CrossRef]

17. Soleimany, F., Jinap, S. and Abas, F. 2012. Determination of mycotoxins in cereals by liquid chromatography tandem mass spectrometry. Food Chem. 130: 1055-1060. [CrossRef]

18. Sulyok, M., Krska, R. and Schuhmacher, R. 2007. Application of a liquid chromatography-tandem mass spectrometric method to multi-mycotoxin determination in raw cereals and evaluation of matrix effects. Food Addit. Contam. 24: 1184-1195. [Medline] [CrossRef]

19. Streit, E., Naehrer, K., Rodrigues, I. and Schatzmayr, G. 2013. Mycotoxin occurrence in feed and feed raw materials worldwide: long-term analysis with special focus on Europe and Asia. J. Sci. Food Agric. 93: 2892-2899. [Medline] [CrossRef]

20. Varga, E., Glauner, T., Berthiller, F., Krska, R., Schuhmacher, R. and Sulyok, M. 2013. Development and validation of a (semi-) quantitative UHPLC-MS/MS method for the determination of 191 mycotoxins and other fungal metabolites in almonds, hazelnuts, peanuts and pistachios. Anal. Bioanal. Chem. 405 : 5087-5104. [Medline] [CrossRef]

21. Waenlor, W. and Wiwanitkit, V. 2003. Aflatoxin contamination of food and food products in Thailand: an overview. Southeast Asian J. Trop. Med. Public Health 34 Suppl 2: 184-190. [Medline]

22. Yibadatihan, S., Jinap, S. and Mahyudin, N. A. 2014. Simultaneous determination of multi-mycotoxins in palm kernel cake (PKC) using liquid chromatography-tandem mass spectrometry (LC-MS/MS). Food Addit. Contam. Part A Chem. Anal. Control Expo. Risk Assess. 31: 2071-2079. [Medline] [CrossRef]

23. Yoshizawa, T., Yamashita, A. and Chokethaworn, N. 1996. Occurrence of fumonisins and aflatoxins in corn from Thailand. Food Addit. Contam. 13: 163-168. [Medline] [CrossRef]

24. Zachariasova, M., Dzuman, Z., Veprikova, Z., Hajkova, K., Jiru, M., Vaclavikova, M., Zachariasova, A., Pospichalova, M., Florian, M. and Hajslova, J. 2014. Occurrence of multiple mycotoxins in European feedingstuffs, assessment of dietary intake by farm animals. Anim. Feed Sci. Technol. 193: 124-140. [CrossRef] 